\title{
Three Species of the Genus Pipunculus Latreille (Insecta: Diptera: Pipunculidae) New to Korea
}

\author{
Sang Jae Suh ${ }^{1}$ and Yong Jung Kwon ${ }^{2, *}$ \\ ${ }^{1}$ School of Applied Ecological Resources, Kyungpook National University, Sangju 742-711, Korea \\ ${ }^{2}$ School of Applied Bioscience, Kyungpook National University, Daegu 702-701, Korea
}

\begin{abstract}
In this paper, three species of the big-headed fly belonging to the genus Pipunculus Latreille are newly reported from Korea: P. avius Morakote, P. emiliae Kuznetzov, and P. rarus Morakote. A key to the Korean species and some photographs on external features are given.
\end{abstract}

Keywords: Taxonomy, Pipunculidae, Pipunculus, Korea

\section{INTRODUCTION}

The big-headed fly genus Pipunculus Latreille is a small group of Pipunculidae, being widely distributed throughout the world, which includes about sixty nine species (Skevington, 2008). The larvae are known as endoparasites of the homopterous insects of the family Cicadellidae (Coe, 1966; Morakote and Hirashima, 1990).

As far as we know, the first record of the genus from Korea was made by Kim (1971), who reported Pipunculus kumamotoensis Matsumura (=Eudorylas kumamotensis) from Seoul. After, Kozanek and Kwon (1992) recorded three species: Pipunculus campestris Latreille, P. subvaripes Morakote and $P$. thomsoni Becker (=P. campestris) from North Korea. Therefore, only two species have been observed in Korean fauna.

In the course of the taxonomic survey on the Korean Pipunculidae, we found three further species belonging to the genus Pipunculus Latreille hitherto previously unrecorded from Korea: $P$. avius Morakote, $P$. emiliae Kuznetzov, and $P$. rarus Morakote.

\section{MATERIALS AND METHODS}

The terminology and classification system adopted in this study follow Kehlmaier (2005, 2008). All voucher specimens examined in the present study were deposited in the collection of the School of Applied Ecological Resources at Kyungpook National University, Sangju.

\footnotetext{
*To whom correspondence should be addressed

Tel: 82-53-950-5764, Fax: 82-53-951-5764

E-mail: yjkwon@knu.ac.kr
}

\section{SYSTEMATIC ACCOUNTS}

Order Diptera Linnaeus, 1758

Family Pipunculidae Walker, 1834

Genus Pipunculus Latreille, 1802

$1 *$ Pipunculus avius Morakote, 1990

Pipunculus avius Morakote, 1990: 222-223 (Type-locality: Japan).

Diagnosis. Female. Body length $5.1 \mathrm{~mm}$, wing length $5.3 \mathrm{~mm}$. Head strikingly large and globular, about 1.2 times as high as long in profile; frons black, silvery microtomentose near the antennae, maximum width slightly wider than the width of the second antennal segment; face densely microtomentose, appearing velvety; haustellum yellowish brown. Antenna (Fig. 1B) with fuscous first and second segments; flagellum yellow. Thorax and scutellum black with gray pollen, sparsely covered with fine brown hairs on the dorsum; postpronotal lobe yellowish brown; pleurae brown tinged; propleuron with long bristle. Legs with black coxae; the other segments yellow; the last tarsal segment more darken; pulvilli whitish yellow, about as long as the last tarsal segments. Wing hyaline; third costal section about 1.4 times as long as the fourth; halter yellowish brown. Abdomen black with thin grayish pollen, sparsely covered with yellow hairs; ovipositor (Fig. $1 \mathrm{C}, \mathrm{D})$ piercer yellow, about 1.5 times as long as the base.

Material examined. 1 우, Chungcheongnam-do, Gyeryongsan, 23 May 1989 (Y.J. Kwon).

Distribution. Korea (new record), Japan.

\footnotetext{
2*Pipunculus emiliae Kuznetzov, 1990

Pipunculus emiliae Kuznetzov, 1990: 385-386 (Type-locality: Mongolia).
}

$1 *$ 노랑참머리파리 (신칭), ${ }^{2 *}$ 북방참머리파리 (신칭) 

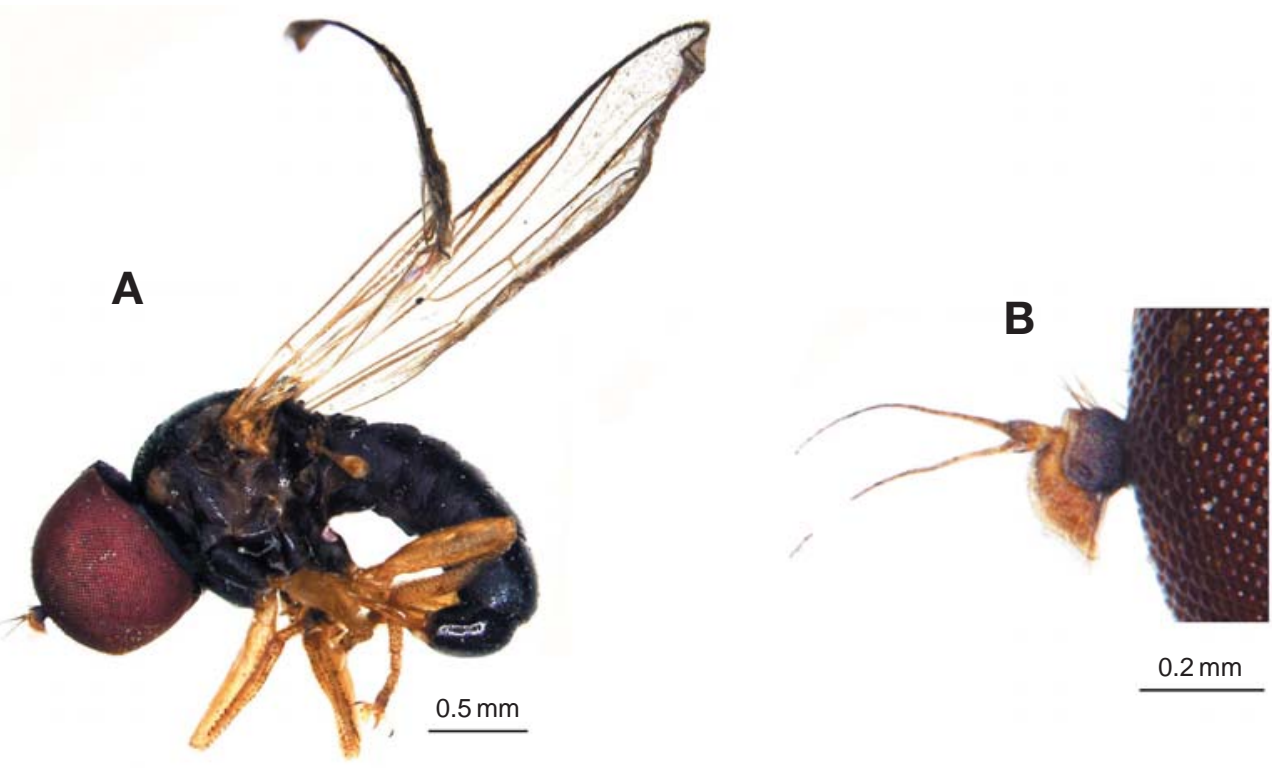

$0.2 \mathrm{~mm}$

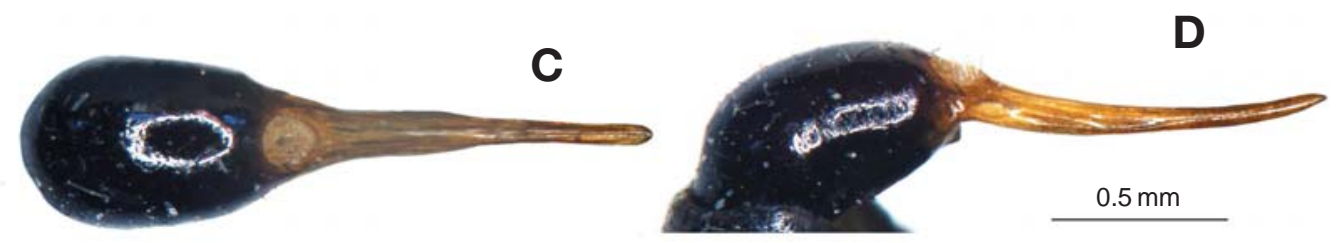

Fig. 1. Pipunculus avius Morakote, 1990, Female. A, habitus; B, antenna; C, ovipositor, dorsal view; D, ditto, lateral view.

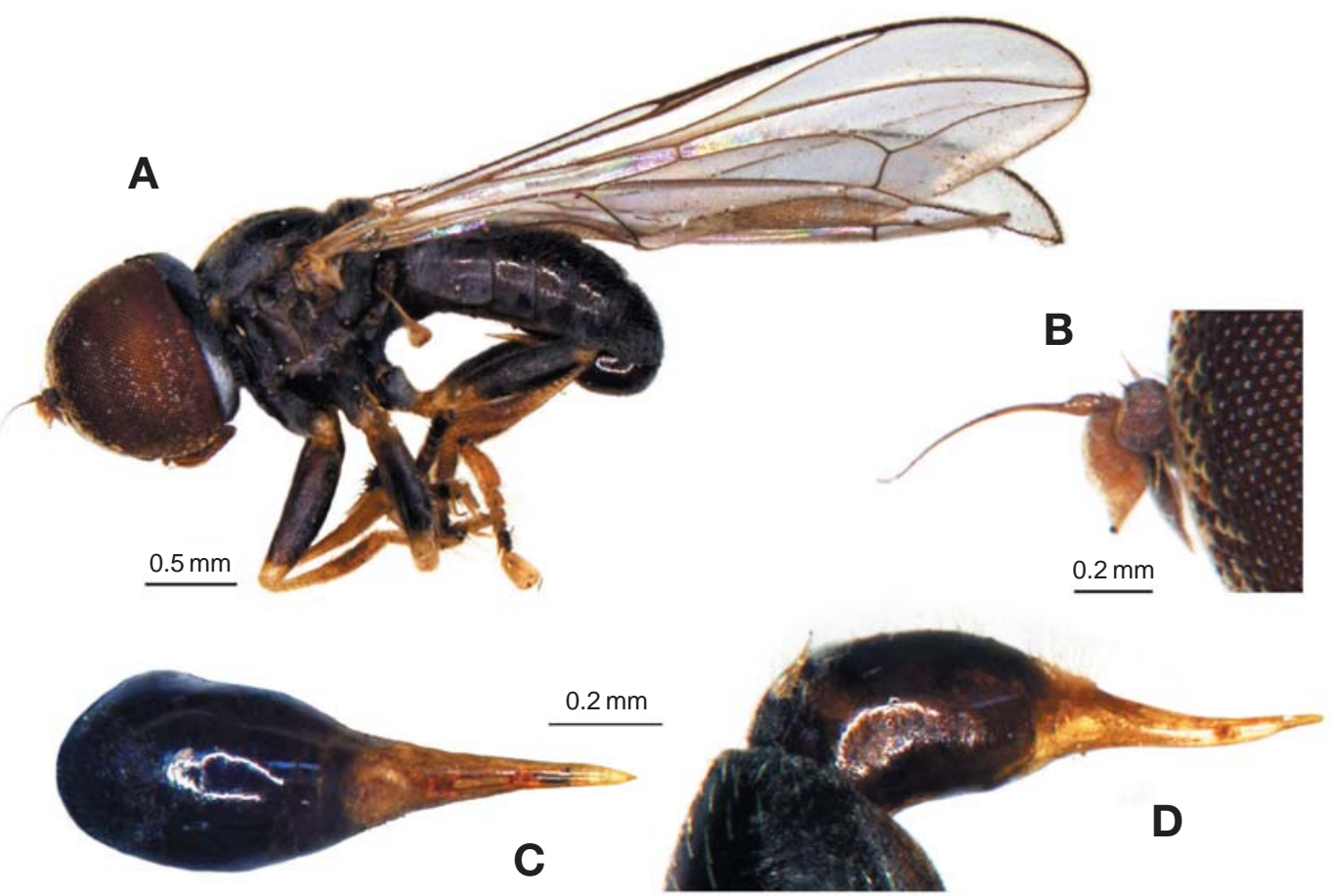

Fig. 2. Pipunculus emiliae Kuznetzov, 1990, Female. A, habitus; B, antenna; C, ovipositor, dorsal view; D, ditto, lateral view. 


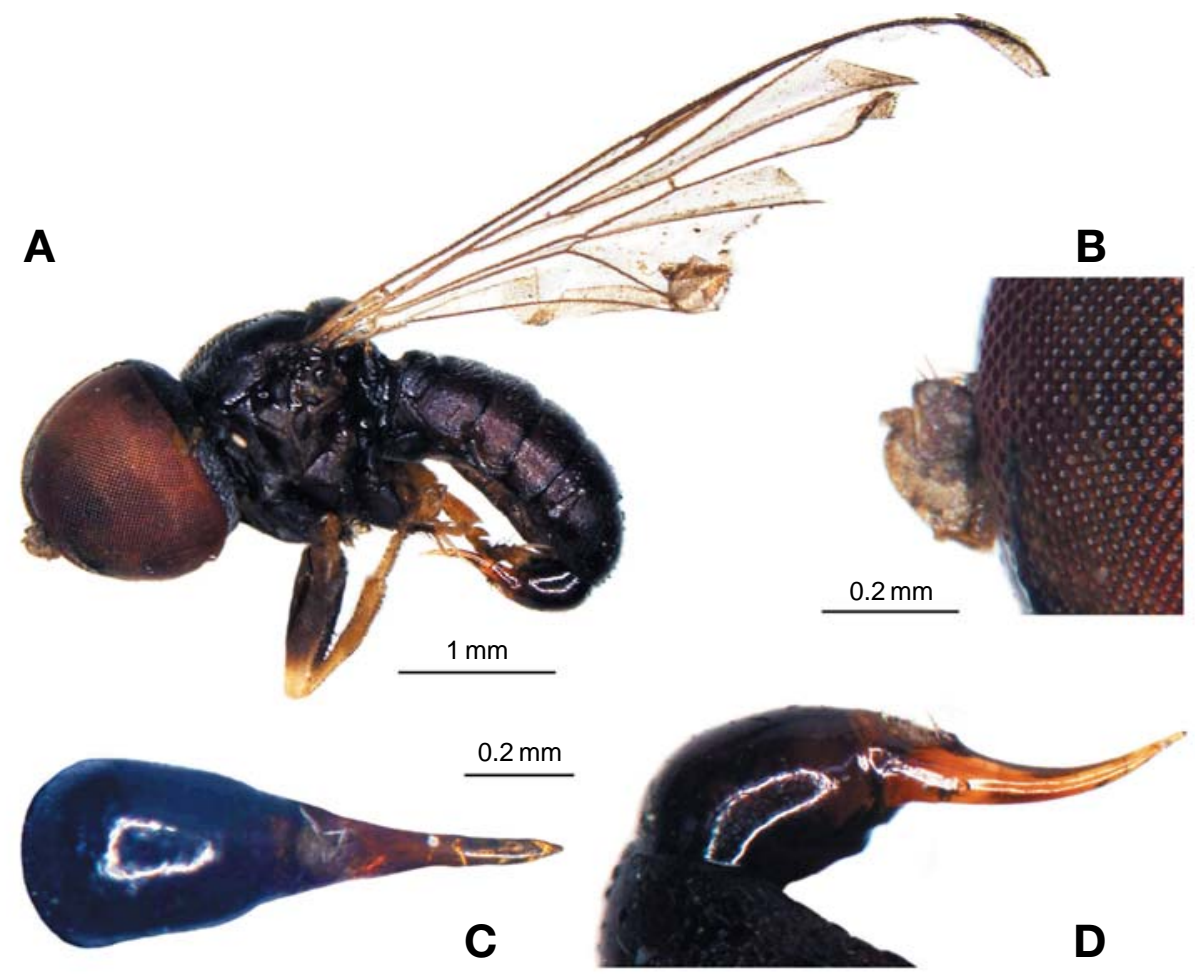

Fig. 3. Pipunculus rarus Morakote, 1990, Female. A, habitus; B, antenna; C, ovipositor, dorsal view; D, ditto, lateral view.

Diagnosis. Female. Body length 3.5-4.2 mm, wing length 4.4-4.7 mm. Head strikingly large and globular, about 1.21.3 times as high as long in profile; frons black, silvery microtomentose near the antennae, maximum width of frons as wide as the width of the second antennal segment; face densely microtomentose, appearing velvety; haustellum brown. Antenna (Fig. 2B) with fuscous first and second segments; flagellum yellowish brown; arista dark brown. Thorax and scutellum subshiny black with gray pollen, sparsely covered with fine brown hairs on the dorsum; postpronotal lobe brown; pleurae with thin gray pollen; propleuron with long bristles. Coxae and femora black; femur with base and apex narrowly yellow; trochanters, tibiae and tarsi yellow; last tarsal segments more darkened; pulvilli whitish yellow, about 1.5 times as long as last tarsal segments. Wing hyaline; third costal section about 1.1-1.3 times as long as the fourth; halter yellowish brown. Abdomen black with thin grayish pollen, sparsely covered with yellow hairs; ovipositor (Fig. 2C, D) piercer yellow, about as long as the base.

Material examined. 2 우 우, Gyeongsangbuk-do, Ulleungdo, 2 Oct. 1981 (Y.J. Kwon).

Distribution. Korea (new record), Mongolia.

\section{$1 *$ Pipunculus rarus Morakote, 1990}

Pipunculus rarus Morakote, 1990: 224 (Type-locality: Japan).

Diagnosis. Female. Body length $3.8 \mathrm{~mm}$, wing length 4.3 $\mathrm{mm}$. Head strikingly large and globular, about 1.2 times as high as long in profile; frons black, silvery microtomentose, the maximum width of frons slight wider than the width of the second antennal segment; face densely microtomentose, appearing velvety; haustellum brown. Antenna (Fig. 3B) with fuscous first and second segments; flagellum yellowish brown. Thorax and scutellum black with gray pollen, sparsely covered with fine brown hairs on the dorsum; postpronotal lobe black; pleurae brown tinged; propleuron with long bristle. Coxae and femora black; femur with base and apex narrowly yellow; trochanters, tibiae and tarsi yellow; last tarsal segments more darkened; pulvilli whitish yellow, about 1.5 times as long as last tarsal segments. Wing hyaline; third costal section about 1.1 times as long as the fourth; halter yellowish brown. Abdomen black with thin grayish pollen, sparsely covered with yellow hairs; ovipositor (Fig. 3C, D) piercer yellow, about 1.2 times as long as the base.

Material examined. 1 우, Jeollanam-do, Wando, 21 Jul. 1984 (Y.J. Kwon).

\footnotetext{
1*검은어깨참머리파리 (신칭)
} 
Distribution. Korea (new record), Japan.

\section{Key to females of Korean Pipunculus}

1. Humeral callus black …......................... P. rarus

- Humeral callus brown to yellowish brown …............ 2

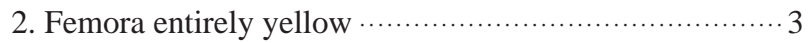

- Femora black except tip …............................. 4

3. Ovipositor piercer greatly long, much longer than the base, extending to first sternite $\cdots \ldots \ldots \ldots \ldots \ldots \ldots \ldots \ldots \ldots$. avius

- Ovipositor piercer moderately long, slightly longer than the base, extending to second sternite $\cdots \cdots \cdot$. . subvaripes

4. Ovipositor piercer thick in dorsal view …...... P. emiliae

- Ovipositor piercer thin and slender in dorsal view

P. campestris

\section{REFERENCES}

Coe, R.L., 1966. Diptera, Pipunculidae. Handb. Ident. Brit. Ins., 10(2): 1-83.

Kehlmaier, C., 2005. Taxonomic revision of European Eudorylini (Insect, Diptera, Pipunculidae). Verh, naturwiss Ver,
Hamburg (N.F.), 41: 45-353.

Kehlmaier, C., 2008. Finnish Pipunculidae (Diptera) studies Part I: Taxonomic notes on Cephalops Fallen, 1810, Pipunculus Latreille, 1802 and Tomosvaryella Aczel, 1939. Zootaxa, 1672: 1-42.

Kim, C.W., 1971. Family 27. Pipunculidae. In Lee, K.W. et al. (eds.) Order Diptera, Illustrated encyclopedia of fauna and flora of Korea, Vol. 12 (Insecta IV), Samhwa Publ. Co., Seoul, p. 888.

Kozanek, M. and Y.J. Kwon, 1992. Contributions to a knowledge of the family Pipunculidae of North Korea (Diptera). Ins. Koreana, 9: 108-114.

Kuznetzov, S.Y., 1990. New species of the family Pipunculidae (Diptera) from Mongolia. Ins. Mongolia, 11: 378-393.

Morakote, R. and Y. Hirashima, 1990. A systematic study of the Japanese Pipunculidae (Diptera). Part IV. The genus Pipunculus Latreille. J. Fac. Agr. Kyushu Univ., 34(3): 215239.

Skevington, J., 2008. Pipunculus. Version 07 August 2008. http:// tolweb.org/Pipunculus/54641/2008.08.07 in The Tree of Life Web Project, http://tolweb.org/(20 Apr. 2010).

Received June 14, 2010 Accepted November 12, 2010 